\title{
Determination of plasma malondialdehyde-like material and its clinical application in stroke patients
}

\author{
MT SANTOS, J VALLES, J AZNAR, AND J VILCHES \\ From the Research Centre and Department of Clinical Pathology, Ciudad Sanitaria 'La Fe', Valencia, \\ Spain
}

SUMMARY Plasma malondialdehyde-like material (MDA-LM) was evaluated in 138 normal subjects and in a group of 57 stroke patients using a modification of the method of Smith et al. (1976). The basal level of MDA-LM in the control group was $35 \mu \mathrm{mol} / 1$ with a range of $22-50 \mu \mathrm{mol} / \mathrm{l}$. Values above $50 \mu \mathrm{mol} / 1$ were found in $80 \%$ of the patients suffering from subarachnoid haemorrhage, in $68 \%$ of those with cerebral thrombosis, and in $17 \%$ with transient ischaemic attacks. None of the patients with cerebral embolism, intracerebral haematoma, or lacunar infarct had values above 50 $\mu \mathrm{mol} / \mathrm{l}$. Significant statistical differences were found between the control group and all the patients except those with lacunar infarcts.

The laboratory techniques generally used in the diagnosis of thrombosis are based on changes in coagulation and fibrinolytic activity, and on the measurement of platelet-released products in plasma as an index of platelet activation. ${ }^{1}$ Although the fibrinopeptide A assay ${ }^{2}$ is more sensitive than evaluation of the platelet-released products in the detection of hypercoagulable states and intravascular thrombosis, ${ }^{3}$ in some conditions, for example, arterial thrombosis, its measurement could be less meaningful. Platelet factor $4\left(\mathrm{PF}_{4}\right)$ and $\beta$-thromboglobulin $(\beta$ TG) tests for the diagnosis of intravascular thrombosis require radioimmunoassay techniques ${ }^{4}$ which are not available in all laboratories. $\mathbf{P F}_{4}$ evaluation of antiheparin activity has low specificity. ${ }^{5}$ Therefore we decided to look for other simple techniques to detect platelet activation in vivo.

Thrombin and other inductors of platelet aggregation release arachidonic acid from the phospholipids of platelets. ${ }^{6}$ This acid is later metabolised by a cyclo-oxygenase, resulting in cyclic endoperoxides $\left(\mathrm{PGG}_{2}, \mathrm{PGH}_{2}\right)$ which are then rapidly converted to stable prostaglandins $\left(\mathrm{PGE}_{2}, \mathrm{PGF}_{2}, \mathrm{PGD}_{2}\right)$, thromboxanes, $\mathrm{C}_{17}$-hydroxyacid (HHT), and malondialdehyde (MDA). ${ }^{7} 8$ MDA determination has been suggested as a convenient assay for the evaluation of platelet function, ${ }^{9-11}$ as a method to monitor the action of new antiplatelet drugs, ${ }^{712}$ as a useful parameter for the control of aspirin therapy, ${ }^{13}$ and

Received for publication 10 March 1980 as a simple nonradioisotopic technique to determine the platelet life-span. ${ }^{14}$

However, MDA-like material (MDA-LM) is not related only to platelets, since MDA is formed in the course of prostaglandin biosynthesis in various tissues $^{15}$ and during the nonenzymatic autoxidation of polyunsaturated fatty acids. ${ }^{16}$ Lipid peroxidation is thought to be involved in various pathological conditions, such as damage to cells and lungs by air pollution, some phases of atherosclerosis, and some forms of liver injury. ${ }^{1718}$ An increase in plasma MDA was found in both clinical ${ }^{19}$ and experimental ${ }^{20}$ chronic inflammatory processes as well as in $\beta$ thalassaemia major. ${ }^{21}$ Therefore, one cannot assume that an increase in plasma MDA-LM should necessarily be related to a platelet activation process, although an increase in plasma MDA-LM has been detected in experimental stroke and in patients with the sequelae of cerebrovascular disorders. ${ }^{22} 23$

Owing to the clinical difficulties sometimes found not only in the detection of thromboembolism but also in the differential diagnosis of the various types of stroke patient, ${ }^{24}$ we decided to study plasma MDA-LM in those patients to see if there is a correlation between plasma MDA-LM concentration and the aetiology of stroke.

\section{Material}

The study comprised 138 normal subjects and 57 patients admitted to hospital with a diagnosis of 
stroke. All the patients underwent clinical evaluation and the following routine tests: electroencephalogram, lumbar puncture, dynamic and static brain scintigraphy, and computerised tomography. Angiography was performed only in selected cases. The patients were classified according to previously established criteria 2526 into one of the following groups: transient ischaemic attack (12), brain infarct secondary to large artery thrombosis (22), lacunar infarct (6), cerebral embolism (6), intracerebral haematoma (6), and subarachnoid haemorrhage (5).

Venous blood was obtained within four days of the onset of the acute event, mixed with $3.8 \%$ sodium citrate in a ratio of $9: 1 \mathrm{v} / \mathrm{v}$ and centrifuged for 15 minutes at $1000 \mathrm{~g}$ to obtain platelet poor plasma (PPP). MDA-LM was determined by a modification of the method of Smith et al. ${ }^{9} 1 \mathrm{ml}$ of $100 \% \mathrm{w} / \mathrm{v}$ trichloroacetic acid in $0.6 \mathrm{M}$ hydrochloric acid and 0.2 $\mathrm{ml}$ of thiobarbituric acid (TBA) reagent were added to duplicates of $0.1 \mathrm{ml} \mathrm{PPP}$ in $0.45 \mathrm{ml}$ of isotonic saline. The TBA reagent was prepared as in Smith's method. ${ }^{9}$ After thorough agitation in a vortex mixer, the samples were heated for 30 minutes in a boiling water bath. After cooling to room temperature, the samples were diluted with $2 \mathrm{ml}$ of distilled water, agitated, and centrifuged in order to obtain a clear solution. The optical density of the pink chromogen
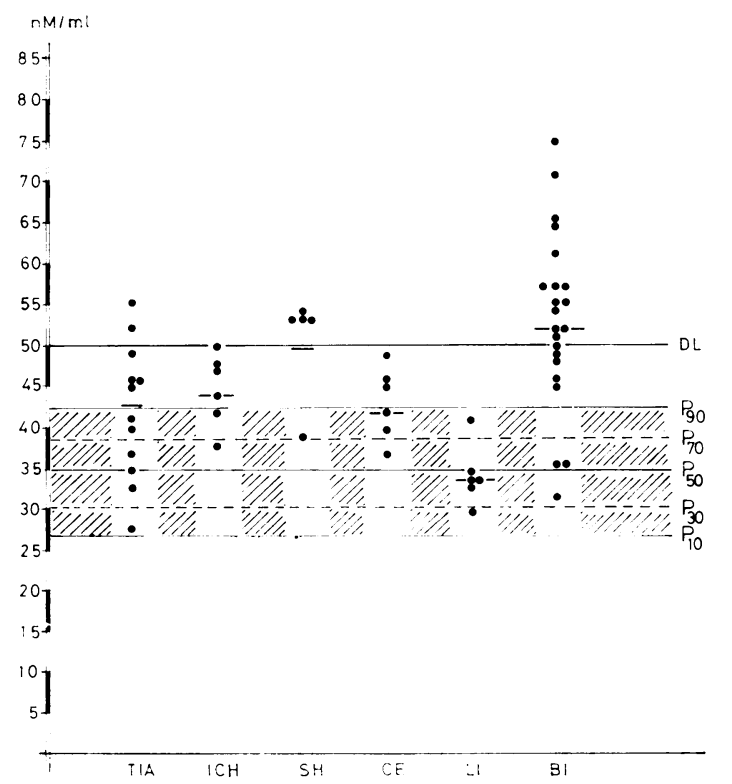

Plasma MDA-LM levels of stroke patients. The hatched area represents the cumulative frequency of the control group: $p=$ percentile $; L=$ discriminatory limit. was read at $532 \mathrm{~nm}$ in a double-beam Beckman Acta III spectrophotometer.

The trichloroacetic acid concentration, the plasma volume as well as the time of the bath were chosen so that the optical density was between $0 \cdot 1$ and 0.2 . With these conditions the chromogen was stable for at least 2 hours.

To quantify the plasma MDA-LM, calibration curves were made with MDA standard in isotonic saline using appropriate dilutions of an MDA stock solution. The molar extinction coefficient was 1.5 $10^{5}$. The recovery of MDA from plasma was $77 \%$ (SD $=8 \cdot 66, \mathrm{n}=66$ ) of that from saline solution; this was taken into account when evaluating the samples. The intra-assay coefficient of variation was $6 \%$. The day-to-day coefficient of variation was $11 \%$. The plasma values of MDA-LM from the normal subjects were arranged as a percentile cumulative frequency (Figure). Student's $t$ test was used as the statistical method.

During the experimental study the laboratory technicians were unaware of the patients' diagnoses, and clinicians who made the diagnoses were unaware of the MDA-LM results when grouping the patients.

\section{Results}

The mean value of plasma MDA-LM in the control group was $35 \mu \mathrm{mol} / 1(\mathrm{n}=138)$, range $22-50 \mu \mathrm{mol} / \mathrm{l}$. The plasma MDA-LM was found to be above 50

Table 1 Plasma MDA-LM concentrations in patients and controls

\begin{tabular}{|c|c|c|c|}
\hline \multirow[t]{2}{*}{ Subjects } & \multirow[t]{2}{*}{ No. } & \multicolumn{2}{|c|}{$\begin{array}{l}\text { Concentration of } \\
M D A-L M(\mu \mathrm{mol} / l)\end{array}$} \\
\hline & & $\overline{\bar{X}}$ & $S D$ \\
\hline Controls & 138 & $35 \cdot 11$ & $5 \cdot 89$ \\
\hline Transient ischaemic attack & 12 & $42 \cdot 75$ & 6.73 \\
\hline Intracerebral haematoma & 6 & $43 \cdot 83$ & $4 \cdot 40$ \\
\hline Subarachnoid haemorrhage & 5 & $49 \cdot 31$ & $6 \cdot 35$ \\
\hline Cerebral embolism & 6 & $42 \cdot 16$ & $4 \cdot 35$ \\
\hline Lacunar infarct & 6 & $35 \cdot 5$ & 3.62 \\
\hline Brain infarct & 22 & $52 \cdot 05$ & $10 \cdot 41$ \\
\hline
\end{tabular}

Table 2 Percentage of subjects with MDA-LM values $\geqslant 44 \mathrm{\mu mol} / \mathrm{l}\left(\mathrm{P}_{95 \%} \%\right), \geqslant 47 \mathrm{\mu mol} / \mathrm{l}\left(P_{97 \%}\right), \geqslant 50$ umol/l (P100\%)

\begin{tabular}{lccc}
\hline Subjects & \multicolumn{2}{l}{$\begin{array}{l}\text { Concentration of } M \text { D A }- \text { LM } \\
(\text { imolll })\end{array}$} \\
\cline { 2 - 4 } & 44 & 47 & 50 \\
\hline Controls & 6 & 2 & $0 \cdot 7$ \\
Transient ischaemic attack & 58 & 17 & 17 \\
Intracerebral haematoma & 50 & 0 & 0 \\
Subarachnoid haemorrhage & 80 & 80 & 80 \\
Cerebral embolism & 50 & 17 & 0 \\
Lacunar infarct & 0 & 0 & 0 \\
Brain infarct & 86 & 73 & 68 \\
\hline
\end{tabular}


$\mu \mathrm{mol} / 1$ in $80 \%$ of the subarachnoid haemorrhage and in $68 \%$ of the large artery thrombosis patients. On the other hand, only $17 \%$ of the patients with transient ischaemic attacks and none of those suffering from embolism or lacunar infarct exceeded the 50 $\mu \mathrm{mol} / 1$ limit (Figure; Tables 1 and 2). All the patients, except for the lacunar infarct group, had a moderate but significant increase in MDA-LM in plasma when compared to the control group.

\section{Discussion}

The thiobarbiturate assay gave colour not only in the supernatant but also in the protein precipitate obtained by the addition of trichloroacetic acid. Therefore, in our method, we evaluated the MDALM in both fractions, unlike other authors who detemined the MDA-LM only in the supernatant ${ }^{27}$ or in the precipitate. ${ }^{23}$ The higher plasma MDA-LM values obtained in our method, as compared to those of other authors, ${ }^{23} 27$ may be due to this.

In the control group, none of the subjects had a plasma MDA-LM above $50 \mu \mathrm{mol} / \mathrm{l}$. We found a plasma MDA-LM greater than $50 \mu \mathrm{mol} / 1$ in $80 \%$ of patients with subarachnoid haemorrhage, in $68 \%$ of those with cerebral thrombosis, and in $17 \%$ of those suffering from transient ischaemic attacks. On the other hand, all the patients with intracerebral haematoma, lucunar infarct, or embolism had values below that limit. Therefore, an increase in the plasma MDA-LM above $50 \mu \mathrm{mol} / 1$, excluding subarachnoid haemorrhage patients, strongly suggests a cerebral thrombosis in stroke patients, although a lower value does not rule out this possibility.

The difference in the plasma MDA-LM values found in patients with subarachnoid haemorrhage and intracerebral haematoma is interesting and could help in the differential diagnosis of both phenomena, which is sometimes difficult to establish by clinical means. ${ }^{24}$ The plasma MDA-LM level and the cerebral damage seem to be unrelated since a positive correlation could not be found between the plasma MDA-LM and the extent of the damage diagnosed by computerised tomography. Also, in some patients in whom cerebral damage was to be expected, normal plasma MDA-LM values were found.

The fact that MDA-LM was elevated several days after the onset of the thrombotic event is difficult to explain at this time since the metabolism of plasma TBA-reactive products is not completely understood. On the other hand, it is known that TBA-reactive materials may alter some cell structures, ${ }^{18}$ especially proteins, ${ }^{17}$ and they may modify the function of some organs as well as play a role in some chronic pathological conditions such as atherosclerosis. ${ }^{17}{ }^{18}$ It has also been shown recently that lipid peroxides selectively inhibit $\mathbf{P G I}_{2}$ synthesis, ${ }^{28}$ a substance with antiaggregant and vasodilator action in vivo. Hence increased levels of plasma MDA-LM could indicate a tendency to intravascular thrombosis.

We acknowledge the technical assistance of Miss Rosa M Ferrer and Miss Carmen Insa.

This work was supported by grant No 12/423/78 from the Instituto Nacional de Previsión.

\section{References}

${ }^{1}$ Sixma JJ. Techniques for diagnosing prethrombotics states. A review. Thrombos Haemostas 1978;40:252-9.

${ }^{2}$ Nossel HL, Ti M, Kaplan KL, Spanondis K, Soland T, Butler VP Jr. The generation of fibrinopeptide $A$ in clinical blood samples. Evidence for thrombin activity. $J$ Clin Invest 1976;58:1136-44.

${ }^{3}$ Kaplan KL, Nossel HL, Drillings M, Lesznik G. Radioimmunoassay of platelet factor 4 and $\beta$-thromboglobulin: Development and application to studies of platelet release in relation to fibrinopeptide A generation. Brit J Haemat 1978;39:129-46.

${ }^{4}$ Bolton AE, Ludlam CA, Moore S, Pepper DS, Cash JD. Three approaches to the radioimmunoassay of human $\beta$-thromboglobulin. Brit J Haemat 1976;33:233-8.

${ }^{5}$ O'Brien JR, Etherington MD, Jamieson S, Lawford P. Heparin thrombin clotting time and platelet factor 4 (letter). Lancet 1974;2:656-7.

6 Bills TK, Smith JB, Silver MJ. Metabolism of $\left({ }^{14} \mathrm{C}\right)$ arachidonic acid by human platelets. Biochim Biophys Acta 1976;424:303-14.

${ }^{7}$ Hamberg M, Svensson J, Samuelsson B. Prostaglandin endoperoxides. A new concept concerning the mode of action and release of prostaglandins. Proc Nat Acad Sci USA 1974;71:3825-8.

${ }^{8}$ Hamberg M, Svensson J, Samuelsson B. Thromboxanes: A new group of biologically active compounds derived from prostaglandin endoperoxides. Proc Nat Acad Sci USA 1975;72:2994-8.

9 Smith JB, Ingerman CM, Silver MJ. Malondialdehyde formation as an indicator of prostaglandin production by human platelets. J Lab Clin Med 1976;88:167-72.

10 Pareti FJ, Mannucci L, Capitanio A, Mills DCB. Malondialdehyde (MDA) formation in patients with defective release reaction. VIth Int Congr Thromb Haem-XII Congr World Fed Hemoph 1977;38:28.

${ }^{11}$ Stuart MJ. Storage pool deficiency in neonatal platelet. VIth Int Congr Thromb Haem-XII Congr World Fed Hemoph 1977;38:4.

12 Zucker MB. Proquazone (Sandoz 43-715): An unusually potent inhibitor of platelet release reaction and malondialdehyde formation. Proc Soc Exp Biol Med 1977;156: 209-12.

${ }^{13}$ Santos MT, Aznar J, Valles J, Fernandez MA. The determination of MDA as a simple technique for the control of the therapy with aspirin. Thromb Res 1979;14:513-8.

${ }^{14}$ Stuart MJ, Murphy S, Oski MB. A simple nonradioisotope technic for the determination of platelet life-span. $N$ Engl J Med 1975;292:1310-3.

${ }^{15}$ Robak J, Sobanska B. Relationship between lipid peroxidation and prostaglandin generation in rabbit tissues. Biochem Pharmacol 1976;25:2233-6.

16 Pryor WA, Stanley JP. A suggested mechanism for the production of malondialdehyde during the autoxidation 
of polyunsaturated fatty acids. Nonenzymatic production of prostaglandin endoperoxides during autoxidation. J Org Chem 1975;40:3615-7.

17 Tappel AL. Lipid peroxidation damage to cell components. Fed Proc 1973;32:1870-4.

18 Plaa GL, Witsch H. Chemicals, drugs, and lipid peroxidation. Ann Rev Pharmacol Toxicol 1976;16:125-41.

19 Muus P, Bonta IL, Oudsten SA. Plasma levels of malondialdehyde a product of cyclooxygenase-dependent and independent lipid peroxidation in rheumatoid arthritis: A correlation with disease activity. Prostaglandins $M e d$. 1979;2:63-5.

${ }^{20}$ Bragt PC, Schenkelaars EPM, Bonta IL. Dissociation between prostaglandin and malondialdehyde formation in exudate and increased levels of malondialdehyde in plasma and liver during granulomatous inflammation in the rat. Prostaglandins Med. 1979;2:51-61.

21 Giardini O, Murgia F, Martino F, Mannarino O, Corrado G, Maggioni G. Serum lipid pattern in $\beta$-thalassaemia. Acta Haemat 1978;60:100-7.

22 Tomita I, Sano M, Serizawa S, Ohta K, Katou M. Fluctuation of lipid peroxides and related enzyme activities at time of stroke in stroke-prone spontaneously hypertensive rats. Stroke 1979;10:323-6.
${ }^{23}$ Satoh K. Serum lipid peroxide in cerebrovascular disorders determined by a new colorimetric method. Clin Chim Acta 1978;90:37-43.

24 Boudouresques G, Hauw JJ, Escourolle R et al. Diagnostic des hémorragies cérébrales. 247 Observations anatomiques. Nouv Presse Méd 1979;8:1479-82.

${ }^{25}$ Committee on cerebrovascular diseases: A classification and outline of cerebrovascular disease II. Stroke 1975;6: 564-616.

26 Mohr JP, Caplan LR, Melski JW et al. The Harvard cooperative stroke registry: A prospective registry. Neurology 1978;28:754-62.

27 Macfarlane DE, Gardner S, Lipson C, Mills DCB. Malondialdehyde production by platelets during secondary aggregation. Thrombos Haemostas 1977;38: 1002-9.

28 Moncada S, Vane JR. Arachidonic acid metabolites and interactions between platelets and blood vessel walls. $N$ Engl J Med 1979;300:1142-7.

Requests for reprints to: Dr Justo Aznar Lucea, Ciudad Sanitaria de la Seguridad Social 'La Fe', Research Center and Department of Clinical Pathology, Valencia, Spain. 